\title{
Life of a Wildflower: Reimagining Meaningful Learning Through Play-Based Pedagogy
}

\author{
Lisa Nontell
}

\begin{abstract}
The author explores tensions between teacher-centered styles of teaching and play-based approaches that invite students to be creators of their own learning. Through narrative inquiry, the author uses a metaphor of wildflowers growing in natural environments to explore a child-led process of learning through play that fosters creativity and deep thinking. Teaching Kindergarten for the first time, the author reflects on challenges of living "secret stories" in the classroom that differ from "sacred stories" of the school's pedagogical practices, feeling a need to create a "cover story" to present her pedagogy as conforming, yet capable and successful.

Today is a crisp fall day, where the sun seems to hang on to every last ounce of summer. The warmth I feel reminds me of the coy reluctance of fall to surrender to winter, yet gusts of frigid temperatures remind me winter is looming. The hares I see, startled by the tennis ball I am throwing for my border collie, scamper along the rough terrain behind my house. My four-year-old son trots behind our dog, shifting all his weight from one foot to the other, resembling a clumsy puppy himself. We return to the house, removing layers of clothing. I am thankful for the open fields so close to my home. I sit my son down in a kitchen chair, explaining to him that we are going to play "hairdresser" next. I notice that his unsymmetrical hairline has become almost as jagged as the terrain and underbrush growing in the field we just came from.
\end{abstract}

As I prepare to start, I am reminded of the days long ago when my sister and I played hairdresser for hours on end. We had a mobile stylist kit, equipped with a comb, mirror, light pink plastic scissors, and even a hair dryer that made sounds when you turned it on. I remember a shift in my interest, developing a love for other avenues of imaginary play centered on animal care, but my sister's love and devotion to becoming a hair stylist evolved with her into her teenage years. When telling our parents of her career aspirations, they responded to my sister, "You can't be just a hairdresser." They encouraged her to leave the "play" behind and consider a more realistic option. One that took more hard work, studying, and training that involved reading textbooks for hours on end. This meant success.

Holding the kitchen scissors to my son's hair, my dominant hand begins to shake. Why is this happening? I remember having such confidence exploring different styles on my dolls and Barbies, with the ease and confidence of a journeyman hair stylist. "It's just cutting hair," I think. It's just cutting hair, so what's the issue?

I no longer feel confident holding these scissors the way I once did as a child. My hand trembles until I begin to make the first cut, compressing and releasing the handles slowly to ensure I can hide the 
damage I am sure to see. I clasp onto each piece of hair tightly in my hand as I begin to cut, watching smooth lines appear. I like it. I feel free. I seem to grow in confidence with each snip, chop, and cut my scissors make into my son's hair. I begin mimicking what I see hair stylists do when I go to a salon to get my hair done, pinching the ends with my fore- and middle-finger to snip directly into the line and create more dimension and layering.

My son, sitting in our kitchen chair, makes me feel an excitement and curiosity about how to style his hair in different ways. I talk to him as if he is an actual customer, asking about his day, his favourite things to do, and how he likes his hair styled. He is thoroughly enjoying this playful experience and our back-and-forth conversation as we take on our pretend roles. I think about my memories growing up of being completely lost in play, creating and re-creating, molding and remolding, an artist whose sculpture is repeatedly broken down and reconstructed to evolve with her. Holding those kitchen scissors, the excitement, the wonder, and the willingness to try new things unleashes a more confident, braver version of myself, one that I had lost growing up.

As children, we have an innate sense of curiosity and questioning that leads us to be natural scientists in how we explore and wonder (Montessori, 1912). Play comes naturally to children. Just as wildflowers shine their beauty in all places, spaces, and circumstances, children at play in unstructured environments are just as natural a phenomenon. Play as a method for learning — so wild, sporadic, and opportunisticis every essence of a wildflower, whose seedlings drift where they may, and thrive at their own pace, on their own terms.

\title{
My Learning Journey
}

\author{
Wildflowers \\ Wildflowers-I envy them. \\ They're brave. \\ Seeds cast by the wind to \\ land where they may, \\ they stay \\ and hold \\ against most hot, most cold. \\ They persevere, roots shallow \\ yet fierce and free. \\ They epitomize to me \\ all that I sometimes \\ yearn to be. \\ Julie Andrews (Rodriguez, 2016)
}

As a child I was always a dreamer, and one that seemed to float between realms of slaying dragons with fallen jack pine branches that lay scattered across my grandmother's lawn, to watching my Dad construct various bug catchers for me out of scrap wood and screen mesh. The gentle breeze that seemed to float me from each of these possibilities throughout the summer stood still as I entered back into the world of 
school. I walked to school each day in my ever-growing commuter town north of Toronto. Blankets of forest that once held trails for family hikes and shaded canopies were quickly becoming replaced with asphalt terraces and constructed city gardens that no longer provided an environment for the drooping bellflower, daisy, and thistle bouquets I would pick for my mother on my way home from school. I remember finding great joy and ease being surrounded by sporadic patches of wildflowers on my walks to and from school. I often wondered how they got there, if they were planted or happenstance, if the wind had carried the seeds until letting go.

I have few memories of Kindergarten, but I do remember often drifting between centers, observing what the other children were doing. We had a water table and there were two boys, Joshua and Ryan, who would often spill water while re-creating tsunami-like waves with various boats and scoops, among other objects. I felt fear for those boys who were not following the procedures laid out for us by Mrs. Hampson.

As my school experience grew, the amount I wandered to different spaces within the classroom lessened. In Grade 3 with Mrs. Malone's classroom, I experienced the rigid structure, high discipline, and systematic manner of teaching, with no room for movement in how the classroom was run or for actual movement outside of my desk. My memories of this year are all of moments that seemed to be spent at this desk. I do not remember any big moments, breakthroughs, or curiosities I had. I just remember wanting to stay completely out of the way, at my desk, and not to create any waves in this still environment. We were perfectly positioned as carefully chosen perennials that lay in a garden bed. Row upon row, perfectly symmetrical in every way. Soil that told us what nutrients we needed, how to grow, what temperature we could acclimatize to, and how much water we would need.

\section{A New Beginning}

Moving to a new school that was built closer to my home in Grade 5 was my fresh start. It was my new beginning of no longer being a struggling student that disappointed my teachers, despite staying at my desk as they told me to. I remember walking out to the tarmac where the other students were gathered, awaiting my name to be called by my newly assigned teacher and to follow him to our portable with the rest of the class. Despite the straps on my backpack being cushioned, I remember their sharp constraint as I dug my hands into the handles, clutching onto my last few breaths of fresh, natural air. Freedom. Lisa Lester.

My new teacher called my name, and I vividly remember my grasp on my backpack straps lessening. I remember looking at my teacher and staring longer than I knew I should have. Growing early at a young age, partly due to my father's $6^{\prime} 7^{\prime \prime}$ frame, I was taller than him. He also had his sunglasses hooked on his ears, yet they were shielding the back of his head instead of his eyes. I liked him already. He seemed different, almost kid-like, in his athletic outfits and silly placement of his sunglasses, causing me to wonder what our year together would be like. I wasn't afraid like I was with Mrs. Malone, with pre-told stories of how her day was run year to year. Later, I would learn that this was his first-year teaching. His name was Mr. Barrett, and he became my favourite teacher. 
I remember it was a sunny September day, the kind of day when kids were still excited to be at school, yet eager to get outside and run, while cooler temperatures began to balance the lingering hot summer sun. Mr. Barrett explained we were going to have a math quiz to see where we were at, and he assured us not to stress as it would not be considered in determining our final grade. I did not hear the latter. Sitting straight up in my seat, I felt ready. This was my chance! I was ready to reinvent myself, Lisa Lester, a student who does not disappoint. My already tall stature seemed even taller with how straight I sat in my seat that moment. I placed my sharpened pencil symmetrical to my eraser at the top of my desk. Looking around at the other students, aligned in rows and symmetry, I felt a sense of comfort in uniformity. A garden bed of annuals, coming together in this new classroom with different experiences, hopes and dreams, yet still the same. I was blending in. I was ready.

I was not ready. Mr. Barrett began reading numbers to us and I was unsure in which notation he expected us to write them. Numerical? Written? I wrote both just in case, frantically trying to keep pace with those around me who seemed to so effortlessly write without worry. Was it happening all over again? Was I just born to be a C/D kid? A wilting perennial about to be plucked? The recess bell rang and, as my classmates rushed outside to play and release their energy, I walked up to Mr. Barrett's desk and begged for a retest. I began to cry and plead, apologizing for not properly listening to the direct instruction. He assured me this test did not mean anything at all and did not define me. Why would he, the gardener, the caretaker of our Grade 5 garden bed, respond to the needs of his individual plants? For so long I was conditioned to feel like we were all the same, requiring the same level of assistance and independence to flourish and blossom in the garden bed of a classroom.

Now as a teacher, I often think back to my school memories and wonder how the other students felt in our Grade 3 environment of rigid structure and mechanical practice. Entering the new school in Grade 5, I wonder if others were also hoping for a fresh start, a second chance, or perhaps an opportunity to show they were more than a "C" or " $\mathrm{D}$ "? Thinking back now, I wonder how this fresh start was an opportunity for me to gain an insight into my limitations, was a reflection of my learning, or, instead, was a window into what I could truly be capable of (Galda, 1998)? With this window of hope and promise of a fresh start, I was able to feel safe in an environment that offered me the opportunity to explore new ideas, fail, and try again, that offered far more than the prescribed opportunities presented to me by Mrs. Malone. Mr. Barrett's philosophy seemed to match ours as students who were craving engagement and experience, and our classroom began to open up from a garden bed to a whole field of possibilities. In school ways, it mirrored my experiences portaging through Algonquin Park, blanketed in vast beech, birch, and hemlock canopies, following dense paths with my father. It mirrored my sense of family and community where I spent endless nights in the care of my aunts and uncles during my parents' shift rotations, learning to contribute, collaborate, and compromise with others my age and not. I think about my early elementary years and wonder about the possibilities that would have been presented if I had been more exposed to an open-ended classroom, one that valued play, movement, and individuality; one where failure did not completely uproot someone. What if my earlier school experiences allowed for the dispersal of roots and the grounding of various seedlings, and provided endless avenues for 
replanting, regrowth, and flourishing? Wildflowers, looking so different and natural, demand our attention through their natural beauty.

\section{Teaching How I've Been Taught}

My early years of teaching always seemed to look the same in September. A new year of new beginnings for my students and me, with classrooms that were covered in laminated word walls, inspirational quotes, and learning strategies to help my students succeed. This past year, I began my sixth year of teaching at a new school in a grade I had never taught before. I was excited to teach Kindergarten; the magic, wonder, and playful curiosity that I experienced with my own four-year-old son at home led me to feeling excited to share a similar experience alongside my students. My school, located in a small, rural town outside of Saskatoon, is known for accomplishments, particularly in literacy. By Grade 3, students who attend our school are expected to be reading at grade level or higher, which is tracked through the Fountas and Pinnell (1996) reading program.

Our schools carry "sacred stories" (Crites, 1971) of how to measure learning and success. Crites explained that a sacred story is often artfully designed and reflective of a certain culture, being one that "informs people's sense of the story of which their own lives are a part, of the moving course of their own action and experience" (p. 295). The idea of a sacred story is applied to schools by Murray Orr (2005), who explained this term is used to represent the unspoken, yet powerful, grand narrative of what the school landscape should look and feel like. For me, I continued to struggle with the tensions that arose from my belief in imaginative play as an authentic and valuable form of learning for Kindergarten, as the sacred story of school did not offer a script that allowed for my vision to be acceptable on the school landscape in which I was situated. This school emulated a Cinderella story, a story of successful reading scores being realized with the same limited number of teachers, educational assistants, and resources as other schools. There was tension between the story I brought with me of how I envisioned children learning, arising from my own narrative history and from my playful experiences with my son, and a story that valued early intervention, routine testing, and rote learning.

It was late fall, and there was a sense of excitement in the air as my Kindergarten class began to sense the wonders that accompany the changing of seasons. Transitions in and out of our classroom became more hurried and congested, as lockers that once held backpacks were now being filled with ski pants, winter jackets, toques, and mittens. I noticed a growing interest among the children in animals and caring for them as discussions within our imaginative playtime often involved caring for pets, herding farm animals, and pretending to be the animals themselves. A corner of our classroom became a pet hospital, lined with cartooned pictures of hospital personnel who would be there ready to help with any sick animal patients. While engaging in this play with them, I first approached the reception desk, attended by a little boy named Brady, who kindly greeted me and asked me what was wrong with my animal. After explaining how I wasn't sure but that I noticed my stuffed animal was limping, he invited me to wait on one of the three chairs in the waiting room as another two students assessed my animal. These veterinary surgeons, doctors, nurses, and receptionists were completely committed to their playful roles in this space, sharing knowledge, joy, and curiosities with one another. 
As I entered this building each day, I carried a secret story of my classroom. As I lived out a story of play, wonder, and exploration in my classroom, I kept this story secret as it did not align with the school story of structure, routines, and testing. I felt a cover story was necessary to better align with the stories around me in this new environment. Connelly and Clandinin (1990) suggested that when our own stories resist the sacred story of school, they do so secretly and, in place, we prepare a cover story to tell outside of our classroom that better aligns with the curriculum image that the sacred story expects.

When teachers move out of their classrooms onto the out-of-classroom place on the landscape, they often live and tell cover stories, stories in which they portray themselves as experts, certain characters whose teacher stories fit within the acceptable range of the story being lived by the school. (p. 25)

I think about the pressure I felt to uphold my cover story of curriculum. As a result, I would pause our wonder and discovery through play to sit in a circle for our letter of the day routine. I struggled with these lessons as they were not designed or delivered to benefit my teaching or my students. This was my cover story; my story that showed to others I was a competent and capable Kindergarten teacher, who valued phonemic awareness and direct instruction of these skills just as I had been taught. This was a component of our day that neither my students nor I looked forward to. It was a "check-off item" on both of our lists to demonstrate we were taking steps toward letter recognition and phonemic awareness, despite the incredible conversation, reflection, and discovery we were engaged in during play. Our letter-of-the-day sharing circle had a much more serious tone to it and writing practice began with teaching through song the proper way to hold a pencil to practice letter-tracing booklets.

Hold the pencil just like this

Push the pointer finger squish, squish, squish

Lay the pencil on the thumb bed

Write all the amazing things in my head.

One of the main problems with songs such as this is they give a false impression of catering to children and how they learn. To some, this may have appeared to be an engaging lesson as it held the students' attention and they all seemed to be following along. As I reflect back, this was my cover story that I would tell to myself and to others. What is not reflected in this story is that each student needed to stay seated in their "parking space," and that I spent time policing behaviour that demonstrated attention was elsewhere. Further, it sent the message that there is one correct way to hold a pencil, and I, the teacher, know it and must teach it to them. Montessori (1912) examined the desire for control in schools, from what children learn, to how they learn, to using the desk, or in my case, the parking space, as a relentless pursuit to dictate how children should learn and what content makes them adequate. In contrast to "the glory of discovery" (p. 22), sitting at a desk demands immobility and forced attention, in which case children become slaves to the mechanics and process of becoming a student. In retrospect, titling my 
own movement as "policing of a parking space," reflected my false sense of understanding what my students needed.

I could not help but feel our class needed these constraints because of how constrained I felt, as their teacher, with pressure to deliver the curriculum and follow suit with the cover story of our school. Any type of play and exploration seemed to be viewed as a reward after the "real work" was done and, even then, students were limited in what and how they could play with the materials. My classroom seemed both loud with frustrated, constrained children who were desperate to fulfil their own natural curiosities, and quiet, with children waiting to be told how to behave, what to do, and what to learn. Was I becoming the teacher that I vowed not to be? Had my own story been altered to meet the stories of others around me? Was I changing my students' perception of what school entailed, and what they were capable of?

My experience this year has taught me that Kindergarten is a year where play is the most needed and is the most controversial. Kindergarten is often the initial school experience for children, and depending on where a student's birthday falls in the school year, they may be four, five, or six years old. Paley (2004) explained how we somehow seem to be misplacing a year with our expectations of these early learners. When I think about the sacred story of school, I cannot help but feel that our five-year-old learners are now expected to know letters, sounds, and numbers upon entry into school despite this being the goal for the end of their Kindergarten year. I felt these expectations as their teacher. I think about four young boys in my class who scored very low on letter and number recognition testing. This knowledge did not reflect Connor's passion for building, Eric's extensive knowledge of dinosaur species, Luke's spatial sense in making and completing puzzles, or Adam's experiences working with his family on his acreage.

There was not only tension for me with the academic knowledge and skills that were valued by the sacred story, but also with the behaviours that were applauded. Noddings (2015) referred to these behaviours in the classroom as "soft skills," the ability to listen, cooperate, and communicate effectively in the culture of the classroom. Such skills reflect more the Grade 1 curricular expectations, developed gradually and experientially through one year of socialization, critical thinking, problem solving, oral expression, and creative construction in a play-based Kindergarten classroom. I struggle with the tensions that arise when emergent learners are asked to demonstrate their understanding through paper-and-pencil activities and seatwork. How can such controlled teaching and learning possibly evoke anything similar to the rich dialogue arising between two students as they brainstorm how to create a marble run as tall as they are, or the precautions that little Mya is taking to serve her guests at her restaurant, using a towel to carefully hand out their orders, asking them to be careful as their meals cool down? Or Cohen, working hard to compromise with Mya on the menu, while simultaneously cleaning and organizing the kitchen supplies to ensure cleanliness measures are satisfactory for their guests? Children, like wildflowers, are adaptable. To bloom, they need the right conditions. They need to form strong roots to build background knowledge to deepen understanding, yet shallow enough to have confidence to drift between wonderings and ideas.

After one month of attempting to teach my Kindergarten students a phonics-focused, "play after real work," organized center-style of learning, I was ready to try a new approach. My focus shifted to fostering classroom language where my students knew that play is the real work. I positioned myself alongside the 
children as a fellow learner and participant, instead of the teacher, a misconstrued all-knowing being. A level of genius, ownership, and agency began to emerge as I expanded the waves of opportunity that facilitated their learning. My class became extremely interested in living things. With the addition of their animal hospital, they began to develop deep questions, wonderings, and curiosities. Increasingly becoming comfortable with play as a space to dwell with ideas, I loved engaging in group discussions with the students, often with no premeditated plan on where I would take them into topics, but instead open to where they would take me. Our knowledge on animal care was becoming extensive. We knew what animals needed to feel comfortable, healthy, and well. We were experimenting with different types of bandaging to comfort swollen joints and broken bones as they recovered in our hospital. We were now considering the knowledge our playful roles as doctors, surgeons, and medical personnel would need to have, including skeletal systems within the animals we were treating. Through examining different examples of animal x-rays, we began to consider how bones are designed purposefully for a function. It was in that moment that two Kindergarten girls explained to me, "We have ribs to protect our heart. Our spine is long because it holds our back together all the way up to our neck and our head. Hey, imagine how long a spine would be on a giraffe!"

A new wave of curiosity, agency, and discovery began to fill our classroom. Boys who hated every ounce of our former writing practice began to jump up and grab notepads from our business center to document what was about to happen. Students who were already convinced they weren't "good" students, who hated sitting still, practicing letter printing, and waiting to be told instruction, became scientists. They made laptops out of construction paper which inspired our "office space," where they would spend hours writing on blank cheques, playing with numbers on calculators, and recording data on clipboards. Smith-Gilman (2018) suggested the need for children to demonstrate knowledge and understanding in creative ways and valuing the process of children's thinking instead of relying on products. The learning and knowledge being shared amongst these children became something organic and meaningful. Their increasing confidence and commitment to these learning spaces suggested to me that they, in fact, knew they were good students because they felt valued, were contributing, and engaged.

Along with a strong need for connection to those around them, there are many layers required to ensure children have deep, meaningful learning. Children are sensory beings, and as such they use cognitive, social, emotional, and physical aspects of themselves to interpret the world around them and make sense of new connections (Carlsson-Paige et al., 2015). When children play, they use what they know to experiment, explore, and construct new concepts that lay a solid, foundational ground for language, literacy, math, science, and the arts (Carlsson-Paige et al. 2015). This type of learning is a natural phenomenon that is student-led, hands-on, and experiential. Honeyford and Boyd (2015) reminded us that play provides an opportunity for children to use their contextual experience to explore complex concepts and think in high-level ways. 


\section{Creating a Studio}

The atmosphere within our classroom began to shift as I began to trust the organic learning that took place amongst the children and how their interests led them to dig deeper in their learning. Our classroom became transformed into one of a studio-a place where children could create, experiment, model, and engage with various materials. Such an environment gave me the opportunity to "[scaffold] children's fluency with multiple symbolic languages, create a context for looking deeply at what interest[ed] children, and ... to understand better children's process for learning" (Gandini, 2005, p. 49). The studio became an opportunity for connection between the students and me as we learned side by side, shared perspectives, and experimented with new ideas. Our classroom transformed to one where multiple spaces supported different interests and learning.

Gandini (2005) stated that, "the studio is a place for learning all kinds of techniques, and a place for research [...] it is not an isolated place where artistic things happen. It is a laboratory of thinking" (p. 49). Play, in an environment such as this, guides children to the pursuit of the impossible, where they rethink, reshape, and relive every aspect of their lives and creatively find solutions to all their storied problems.

Once I began to reinvent and reimagine these learning spaces as well as the student and teacher roles within them, real and meaningful learning took place. My intention for using these spaces became playful invitations that invited students to experience their learning by living the process of it. Through conversations with my students about what interested them, together we set up spaces, such as an animal hospital, measurement lab, bakery, kitchen, artist studio, and business center. Gray (2013) affirmed the importance of these opportunities being lived experiences, where even in a very scientific domain like biology, individuals "do" biology and play with different ideas to reaffirm existing facts while simultaneously creating new theories.

In his autobiography, Albert Einstein (1949), a leader in genius curiosity, innovation, and creativity, explained how he always loved playing with concepts of math and science but hated studying it in school. For schooling to be truly effective, it is important that students and teachers are comfortable in the dwelling space of an idea-a dwelling space that requires creating theories, revising those theories, and possibly ridding them entirely to create new ones. Paley (2004) explained how children do not require a finalized product to prove learning or to feel successful: "They are always in Act One, on the first rungs of the ladder, preferring to linger there awhile. The children want to discover what the next question might be, before receiving too many answers from the grownups" (p. 75). Play invites learning because it affords children the opportunity to use a genius-level intellect in how they perceive, question, and execute functions to interpret both reality and fantasy circumstances.

\section{Seeds for the Future}

I continue to cut my son's hair and am drawn back to the present moment as he opens up to me about a scary dream that he had the night before. I wonder why he did not mention this dream to me earlier in the day. I wonder if it is our playful roles that are providing him space to do so. He explains to me how 
he was scared because people were chasing him, but then when he put on his Spider-Man costume, he was able to defeat them and save the day. Through becoming Spider-Man, he gains a sense of confidence and ability that he did not previously feel as Ashton. Play created a space for Ashton to tell me an experience and it positioned me to listen.

As I finish his haircut, I sit back to admire the beautifully curious little boy who sits before me. I know our shared playful experiences help him to build key foundational understandings of the world around him and to create new theories about how his world works. My Ashton is a wildflower, drifting between spaces, ideas, and theories faster than Spider-Man, becoming strong, resilient, and creative because of it.

Wildflowers, often viewed as unruly and wild, are wonderful examples of the beauty of persistence and natural process. At times they thrive in clusters, at other times alone. Yet they stand tall, sharing beautiful colours of yellow, blue, pink, and purple, with complete confidence and brilliance. Perhaps in schools we require a similarly natural process, one of play, growth, and exploration. Children, like wildflowers, grow best in the most natural of conditions.

\section{References}

Carlsson-Paige, N., Bywater McLaughlin, G. B., \& Wolfsheimer Almon, J. W. (2015). Little to gain and much to lose. Alliance for Childhood.

Connelly, F. M., \& Clandinin, D. J. (1990). Stories of experience and narrative inquiry. Educational Researcher, 19(5), 2-14.

Crites, S. (1971). The narrative quality of experience. Journal of the American Academy of Religion, 39(3), 291-311.

Einstein, A. (1949). Autobiography. In P. Schilpp, Albert Einstein: Philosopher-scientist. Library of Living Philosophers.

Fountas, I. C., \& Pinnell, G. S. (1996). Guided reading: Good first teaching for all children. Heinemann.

Galda, L. (1998). Mirrors and windows: Reading as transformation. In T.E. Raphael \& K. H. (Au (Eds.), Literature-based instruction: Reshaping the curriculum (pp. 1-11). Christopher-Gordon.

Gandini, L. (2005). In the spirit of the studio: Learning from the atelier of Reggio Emilia. Teachers College Press.

Gray, P. (2013). Free to learn: Why unleashing the instinct to play will make our children happier, more self-reliant, and better students for life. Basic Books.

Honeyford, M. A., \& Boyd, K. (2015). Learning through play: Portraits, photoshop, and visual literacy practices. Journal of Adolescent \& Adult Literacy, 59(1), 63-73.

Montessori, M. (1912). A critical consideration of the new pedagogy in its relation to modern science. In D. J Flinders \& S. J. Thornton (Eds.), The curriculum studies reader (pp. 19-31). Routledge.

Murray Orr, A. (2005). Stories to live by: Book conversations as spaces for attending to children's lives in school. Unpublished doctoral dissertation, University of Alberta, Edmonton, Alberta. (LRP) 
Noddings, N. (2015). The common core standards. In D. J Flinders \& S. J. Thornton (Eds.), The curriculum studies reader (pp. 449-460). Routledge.

Paley, V. (2004). A child's work: The importance of fantasy play. University of Chicago Press.

Rodriguez, C. (2016, June 20). To be a wildflower \#MondayMusings [Web log post]. https://everydaygyaan.com/to-be-a-wildflower/

Smith-Gilman, S. (2018). The arts, loose parts and conversations. Journal of the Canadian Association for Curriculum Studies, 16(1), 90-103.

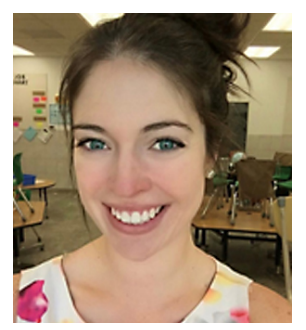

Lisa Nontell is a Kindergarten teacher in central Saskatchewan who has lived in the prairies since 2013. Moving from Ontario, she has grown an appreciation for the vast prairie landscape and open skies of the province she now calls home. Her research interests focus on outdoor learning and play-based pedagogy to foster creativity, stewardship, and innovation in early learning. Graduating from the MEd program, Department of Curriculum Studies, University of Saskatchewan in 2020, she plans to continue her research through doctoral studies that will focus on the early learning practices of inquiry, play, and emergent curriculum. 